\title{
Targeting the Inflammatory Pathway as a Therapeutic Tool for Major Depression
}

\author{
Cristiano Noto $^{a, b}$ Lucas B. Rizzo ${ }^{a}$ Rodrigo B. Mansur ${ }^{a-c}$ Roger S. Mclntyre ${ }^{c}$ \\ Michael Maes ${ }^{d, e} \quad$ Elisa Brietzke ${ }^{a, b}$ \\ anterdisciplinary Laboratory of Clinical Neuroscience (LINC) and b Program for Recognition and Intervention in \\ Individuals in At-Risk Mental States (PRISMA), Department of Psychiatry, Federal University of São Paulo, \\ São Paulo, Brazil; ' $M o o d$ Disorders Psychopharmacology Unit (MDPU), University Health Network, University of \\ Toronto, Toronto, Ont., Canada; ${ }^{\mathrm{d}}$ Department of Psychiatry, Deakin University, Geelong, Vic., Australia; \\ e Department of Psychiatry, Chulalongkorn University, Bangkok, Thailand
}

\section{Key Words}

Depression · Inflammation · Cytokines

\begin{abstract}
In the last decades convergent findings from several lines of evidence has revealed a robust association between major depressive disorder (MDD) and inflammatory pathways. Despite this, the translation of these findings into new and better treatments for MDD has not occurred. The objective of this study is to comprehensively review what is already known with reasonable certainty on inflammatory pathways in MDD, to clarify some points that have been insufficiently studied and to discuss the implications of these findings for future studies targeting inflammatory pathways as a therapeutic tool for individuals with MDD. O 2014 S. Karger AG, Basel
\end{abstract}

\section{Introduction}

Activation of inflammatory pathways is a characteristic of several chronic diseases and, in the last decades, convergent findings from several lines of evidence has revealed a robust association between major depressive disorder (MDD) and inflammation and immune activation [1-3].
More specifically, depression is accompanied by cell-mediated immune (CMI) activation and a chronic mild inflammatory response. In spite of this, we are far from the incorporation of these findings into new and better treatments for people living with MDD. Bridging the gaps of knowledge about inflammatory pathways and mood disorders requires knowledge in more detail on the causative, consequential and concurrent relation between these factors. The objective of this study is to comprehensively review what we already know, to clarify some points that have been insufficiently studied and to discuss the implications of these findings for future studies targeting inflammatory pathways as a therapeutic tool for individuals with MDD.

\section{What Do We Know about Inflammatory Pathways in MDD?}

\section{Individuals with MDD Present a Persistent and} Low-Grade Inflammatory and CMI Activation

The finding that individuals with MDD present activation of inflammatory pathways is a highly reproduced and convergent finding in case-control, postmortem [4], cross-sectional and longitudinal studies in humans and animal models $[5,6]$. In cross-sectional studies, many proinflammatory cytokines, or their receptors or receptor an-

\section{KARGER}

E-Mail karger@karger.com

www.karger.com/nim
(C) 2014 S. Karger AG, Basel

1021-7401/14/0213-0131\$39.50/0
Elisa Brietzke

Rua Pedro de Toledo 980, 3rd Floor

São Paulo, SP 04039-002 (Brazil)

E-Mail elisabrietzke@ hotmail.com 
tagonists, are associated with MDD, including IL- $1 \beta$, IL-2, IL-6, IFN- $\gamma$, TNF- $\alpha$, IL-6R and IL-1RA [7-10]. In addition to increased cytokine levels, depressed patients also show other signs of inflammation, such as an acute-phase response (increased haptoglobin, lower albumin) and activated complement cascades (increased C3 and C4) [2]. Other signs of cell-mediated immune activation include increased levels of neopterin, soluble CD8 molecule and lower levels of plasma tryptophan and increased tryptophan catabolites. Depression is also accompanied by lowered levels of plasma CC16, an endogenous anti-cytokine that inhibits the production of pro-inflammatory cytokines [11]. Lowered CC16, therefore, may contribute to the inflammatory response in MDD. Three recent metaanalyses show higher concentrations of TNF- $\alpha$, IL- 6 , IL-1, sIL-2R and/or C-reactive protein (CRP) in patients with depression $[7,12,13]$. In studies with postmortem brain tissue samples from the prefrontal cortex, Dean et al. [4] found increased levels of TNF transmembrane and, more recently, Shelton et al. [14] found an upregulation of several pro- and anti-inflammatory cytokines, such as IL-1 $\alpha$, IL-2, IL-3, IL-5, IL-8, IL-9, IL-10, IL-12A, IL-13, IL-15, IL-18, IFN- $\gamma$ and lymphotoxin- $\alpha$ in psychotropic drugfree individuals with a history of MDD.

In rodents, induction of a systemic inflammatory response through administration of pro-inflammatory cytokines, such as TNF- $\alpha$, IL- 1 and IFN- $\gamma$, and lipopolysaccharide, LPS, provokes depressive-like behavior, including anhedonia [15-18]. More importantly, sustained production of IL- 6 and IFN- $\gamma$ in transgenic mice is accompanied by the onset of depressive-like behavior [19, 20]. Chronic mild stress and learned helplessness in the rodent are accompanied by peripheral activation of immune-inflammatory pathways [21].

Although most works report immune activation in MDD, there is compelling data suggesting immune suppression. In a meta-analysis, Zorrilla et al. [10] considered this paradox - MDD seems to be accompanied by leukocytosis (mainly due to an increase in the percentage of neutrophils), elevation of B cells, CD4 and activation markers (HLA-DR and CD25) and pro-inflammatory cytokines. Despite the elevation of these markers of immune activation, leukocytosis occurs with shrinkage of the lymphocyte and monocyte population, and reduction of NK and T cells. Regarding cell function, low proliferation by lymphocytes in response to Con A, PWN and PHA, hindered neutrophil phagocytosis and lower NK cytotoxicity was associated with MDD. These data suggest that both adaptive and innate immunity may be impaired in MDD.
Other pathways related to inflammation and CMI activation have been explored recently. Increased oxidative and nitrosative stress (O\&NS) may be in part a consequence of elevated pro-inflammatory cytokines and CMI activation, leading to lipid peroxidation and DNA damage, deregulating the immune response [2, 22]. Moreover, many studies have demonstrated lower levels of antioxidants, such as coenzyme Q10, vitamin E and glutathione in depressed patients, predisposing towards increased O\&NS and damage to fatty acids, proteins, DNA and mitochondria by O\&NS $[2,22]$.

Individuals with MDD Are a Heterogeneous

Population and May Exhibit Differences in

Inflammatory Patterns

Recently, inter-individual differences in the severity of inflammatory changes have been explored. A comparison between individuals with MDD with melancholic characteristics and a group of patients with atypical characteristics indicated that inflammatory changes are more pronounced in the first group, showing more significant abnormalities in TNF- $\alpha$ levels, CRP and IL-6 [23]. In addition, the increased numbers of MDD patients examined in different studies permitted the analysis of subgroups in a meta-analysis and meta-regression. The effect of MDD on IL- 6 and IL-10 levels was significantly larger in subgroups with the diagnosis of MDD compared with those with only depressive symptoms, and in subgroups where individuals were recruited from inpatient or outpatient settings compared to the community [24]. The effect was also larger in those participants who were not selected for a particular comorbidity compared to those selected for cardiovascular disease [24].

\section{The Link between MDD and Cardiovascular}

Conditions Is at Least Partially Mediated by

\section{Inflammatory Pathways}

The relation between acute myocardial infarction (AMI) and depression has long been explored. Nowadays, this association is well established, with a review demonstrating that patients who suffered an AMI have a prevalence of depression three times higher compared to the general community [25]. Remarkably, an MDD diagnosis is present in $15-20 \%$ of AMI patients [25]. On the other hand, depression increases the risk of cardiovascular events. A depressive mood alone is a predictor of coronary heart disease, with a relative risk (RR) of 1.49 (95\% CI 1.16-1.92), wherein a full diagnosis of $\mathrm{MD}$ is an even stronger predictor, with an RR of 2.69 (95\% CI 1.63-4.43) [26]. Several mechanisms are thought to underlie this in- 
teraction, including stress, diet and lifestyle. Among these, various inflammatory processes have been considered to be of pivotal importance, including increased levels of pro-inflammatory and Th1-like cytokines, CRP, haptoglobin, oxidized LDL-cholesterol antibodies, oxidized phospholipids, and lowered levels of antioxidants, including glutathione, vitamin E and coenzyme Q10 $[2,27]$.

\section{The Effect of Stress on the Development of MDD Can}

Be Partially Mediated by Inflammatory Changes

Stress has been associated with a pro-inflammatory profile $[28,29]$ and usually occurs in association with MDD and conflicting relationships, enhancing immune dysregulation $[29,30]$. The general reaction to stress includes both activation of sympathetic tonus and activation of the hypothalamus-pituitary-adrenal (HPA) axis. Acutely, activation of the immune system in stressful situations is physiological, but intense and sustained persistence of stress is able to chronically activate the HPA axis, leading to reductions in cortisol levels by downregulation of hypothalamic cortisol receptors and, in the end, to loss of the regulatory effect of cortisol in the inflammatory system [31]. The well-known effect of stress in autoimmune and inflammatory conditions was the base for the investigation of the role of stress in increased severity of inflammatory imbalances in MDD. In fact, individuals with MDD who report childhood maltreatment present more severe inflammatory changes than those who report the absence of these experiences [32]. In rats exposed to chronic stress the levels of IL-1 were increased [33].

\section{Neuroprogression: Inflammatory Mediators Can}

Potentially Contribute to the Structural, Functional and Cognitive Changes Reported in MDD

In MDD, some clinical features suggest neuroprogression, which is a progressive process of neurodegeneration, with reduced neurogenesis and neuroplasticity and increased neural apoptosis $[34,35]$, manifested by increased illness severity over time, longer and more frequent episodes, and more spontaneous episodes in later stages [36]. Inflammatory processes were associated with both structural and functional anomalies found in MDD patients. Depressed patients show evidence of both proinflammatory changes and neurophysiological abnormalities such as increased amygdala reactivity and volumetric decreases of the hippocampus and ventromedial prefrontal cortex. In addition, in individuals with MDD, there are some studies reporting a modulatory effect of inflammation in cognition, with increases in IL- 6 being related to reduction in verbal memory [37].

Targeting the Inflammatory Pathway as a Therapeutic Tool for MDD
Furthermore, increased pro-inflammatory cytokines may be associated with neuroprogression [36], as evidenced by the involvement of TNF- $\alpha$ in glutamate neurotoxicity process [38] and IL-2 enhancing the action of $\mathrm{N}$-methyl-D-asparate, resulting in astrogliosis, myelin damage and neuronal loss [39]. In the same line, inflammatory pathways may contribute to the staging of depression. TNF- $\alpha$ and IL- 6 were associated with treatment resistance to antidepressants [34]; over time pro-inflammatory cytokines may mediate a sensitization in the inflammatory response to stressors, resulting in a higher susceptibility of new depressive episodes $[34,36]$.

\section{Traditional Antidepressants Modulate Immune}

\section{Activity}

Antidepressants, including tricyclic antidepressants, selective serotonin reuptake inhibitors (SSRIs) and serotonin and norepinephrine reuptake inhibitors, possess in vitro immunosuppressive or negative immunoregulatory effects by suppressing the production of pro-inflammatory cytokines and Th1-like cytokines, such as IFN- $\gamma$, and increasing that of IL-10, a negative immunoregulatory cytokine [40-42].

In rodents, pre-administration of fluoxetine or paroxetine reduced LPS-induced inflammation and depressive-like behaviors [43]. In humans, a meta-analysis was performed exploring Alzheimer's disease (AD) effects on IL- $1 \beta$, IL- 6 and TNF- $\alpha$ in MDD patients. It was found that $\mathrm{AD}$ treatment reduces IL- $1 \beta$ and possibly IL- 6 levels, but not TNF- $\alpha$ levels, despite symptom improvement. When different ADs were analyzed, a possible effect of SSRIs in IL- 6 and TNF- $\alpha$ levels was found [44].

\section{What Do We Not Know about Inflammation in MDD?}

\section{Do Changes in Peripheral Inflammatory Mediators} Predict Central Changes?

The observation that a dye failed to penetrate the brain suggested to Ehrlich [45] in 1885 the existence of a bloodbrain barrier (BBB), which was able to partially isolate the central nervous system (CNS). The structure of the BBB has systematically been studied since that time, revealing an organized composition of different cell types. The inner part of the physical barrier is composed by a specialized endothelium that acts like a moderator between blood and the brain. The brain microvascular endothelial cells have a homogenous thickness, with no transendothelial fenestrations and uninterrupted tight junctions. Paracellular flux is limited to essential molecules only by 
specific transporters. BBB is also composed by astrocytic endfoot processes which cover almost the entire vasculature [46]. Although the BBB has an important role in maintaining the separation of the CNS from the immunological system, nowadays there are questions about whether the CNS is truly immune-privileged.

Cytokines are not small enough to cross the BBB. However, it has been demonstrated that the immune system and the CNS can interact in normal conditions by different pathways. Cytokines generated in the periphery can enter the CNS by leaky regions without a BBB-like choroid plexus and circumventricular organ regions [47, 48]. Also, cytokines can reach the CNS by saturable transporter systems, as has been reported for IL-1, IL-1 antagonist, TNF- $\alpha$ and IL-6 [49]. Furthermore, the vagus nerve can play a role in the immune system/brain communication. Vagus afferent fibers are activated by IL-1, and its integrity is necessary to induce hyperthermia [50]. Lymphocytes can also be found in the CNS, but the process by which they cross the intact BBB is still obscure $[46,51]$.

The pathways linking the immunological system and CNS are not yet completely understood. However, there are several pathways by which the low-grade inflammation and CMI activation can be translated into neuroinflammation and microglial activation, and consequently may drive behavioral changes.

\section{What Is the Primary Source of Abnormalities in Inflammation in MDD?}

The primary source of abnormalities in inflammatory mediators has not been completely elucidated, although there are some plausible hypotheses (fig. 1). The first is genetics. There have been some association studies exploring polymorphisms in cytokine genes, including IL-1 [52]. Initiatives to map the genome of individuals with MDD in genome-wide association studies found that TNF- $\alpha$ was identified as the only gene for which the association with MDD remained significant after correction for multiple testing [53].

The second possible source is environmental. Epigenetic changes produced in early life and provoked by environment adversities have been considered as a potentially pivotal factor in the determination of permanent reprogramming of the HPA axis and inflammatory system [23]. Only very recently, epigenetic aspects of the regulation of cytokines has begun to be explored in MDD, with methylation microarrays to assess genome-wide methylation profiles, but without conclusive results [54]. In addition, interaction with pathogens and other antigens during the development of the immune system has also been considered relevant.

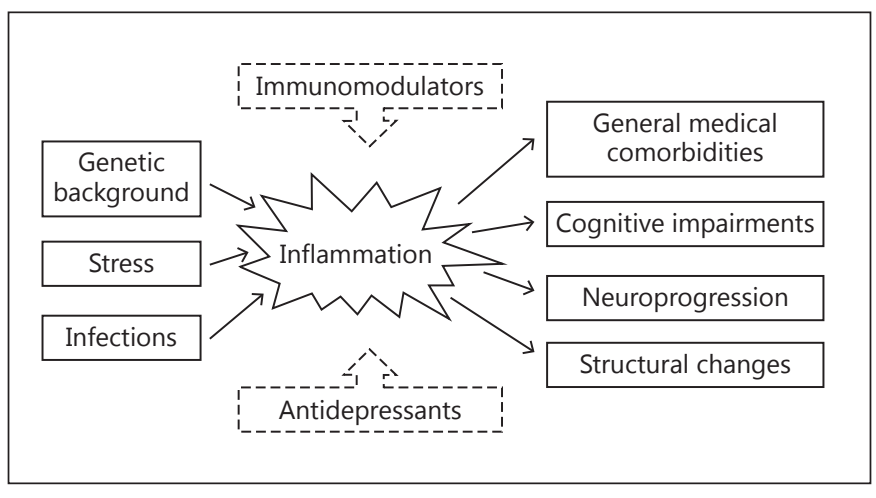

Fig. 1. Trigger factors of depression, the inflammatory pathway and its consequences.

It cannot be dismissed that the influences of both genetic and environmental factors interact during development to produce vulnerability to MDD. One example of this interaction is the study of Haastrup et al. [55], where the major C allele of the IL-18 rs187238 and the major G allele of rs1946518 had a significantly higher prevalence among the patients with a stressful life event prior to the onset of MDD than both patients without a stressful life event and healthy controls.

\section{Do Inflammatory Pathways Predict Treatment \\ Response to Antidepressants?}

A possible application of inflammatory biomarkers in MDD is their use as predictors of response to antidepressants. TNF- $\alpha$ plasmatic concentrations are significantly reduced in responders to treatment with amitriptyline [56]. In another study, early responders and early nonresponders showed opposite trends in cytokine levels during duloxetine treatment. Nonresponders showed a baseline Th2 shift compared to controls (decreased IL-1, IFN- $\gamma$ and TNF- $\alpha$ ), with an increase in Th1 cytokine levels during treatment (increased IL-1, IL-12, IFN- $\gamma$ and decreased IL-10) [57]. In spite of this interesting result this subject remains largely unexplored, albeit with the same promising biomarkers, such as lowered zinc as a marker of treatment-resistant depression [58].

\section{Are Alterations in Inflammatory Mediators in MDD \\ Cause, Consequential or Epiphenomena?}

Despite the evidence of the association between inflammation and CMI activation and MDD, the pathological mechanism remains elusive. It is unknown if immune deregulation is a cause or a consequence of MDD, or just an epiphenomenon. Animal studies show that administration 
of pro-inflammatory cytokines and Th1-like cytokines induce depressive-like behavior in the rodent, indicating that inflammatory mediators can directly cause depression or at least some features of it [2]. From a neurobiological point of view this effect may be subserved by the influence of inflammatory markers in neuroplasticity processes, in monoamine metabolism and in the glutamate-kynurenine pathway, which could lead to an increase in vulnerability to the development of depression [59]. This hypothesis is supported by the well-known induction of depressive symptoms by exogenous cytokine administrations, such as treatment with IFN- $\alpha$ [60]. On the other hand, some pathophysiological processes of depression have been recognized to affect inflammatory activity. Psychosocial stress, both acute and chronic, is one of the main risk factors for the development of MDD [61] and has also been shown to deregulate inflammatory response, an effect likely mediated by the HPA axis and the sympathetic nervous system (SNS) function [62]. Therefore, the dysfunction of the stress-response system observed in depression could, consequentially, lead to inflammatory abnormalities. Finally, other factors related to MDD that also impact on inflammation may explain this association. Obesity and depression have been shown to be connected. Studies have documented a correlation between increased body mass index and a higher probability of developing $\mathrm{MDD}$, and also that depression can be a risk factor for the development of obesity $[63,64]$. Adipose tissue and adipocytes have been linked to an increased production of several inflammatory markers, including IL- $1 \beta$, IL- 6 and TNF- $\alpha$ $[65,66]$, which can be thought of as a mediator of the depression-obesity relation, but it also could be considered an unrelated factor. Gut microbiota has recently been attracting some attention as it was shown to interact with stress-response systems, as well as with inflammatory pathways, and could also be implicated in MDD pathophysiology [59].

Taken together, the evidence indicates that the most likely scenario is of a multifaceted, bidirectional relationship between depression and inflammatory pathways, which is also influenced by different factors, through a network of multiple interacting networks. In this case, activation of the inflammatory pathway would not be the cause, consequence or epiphenomenon of MDD, but, instead, a combination of all three.

\section{The Future of Research on Inflammation in MDD}

In spite of the considerable advance in understanding of the cross-talk between the brain and the immune system, our current belief is that it is time to investigate how these findings can be translated into therapeutic interventions for MDD targeting inflammation. This would be realized by investigating two avenues.

\section{Antidepressant Effects of Anti-Inflammatory and Antioxidant Agents}

As the role of inflammatory pathways in the pathophysiology of depression has become increasingly understood, the use of anti-inflammatory agents in treatment is seen as the logical next step. Several agents have been tested so far, including celecoxib, naproxen, aspirin and TNF- $\alpha$ antagonists. Celecoxib was used as an adjuvant to reboxetine in a 6-week placebo double-blind, randomized controlled trial (RCT) for 40 individuals diagnosed with MDD [67]. Subjects that used celecoxib at a dose of $400 \mathrm{mg}$ /day presented a significant improvement in depressive symptoms compared to the placebo group [67]. Another RCT tested celecoxib as an add-on to fluoxetine, showing the superiority of the association [68]. Celecoxib has also shown promising results as an adjuvant in the treatment of bipolar depression and schizophrenia [69-71], but has negative results in improving depressive symptomatology in cognitively normal volunteers aged 70 years and older with a family history of Alzheimer-like dementia [72].

The efficacy of aspirin was evaluated by an open-label study that employed $160 \mathrm{mg} /$ day of aspirin as an adjuvant in $24 \mathrm{MDD}$ patients with no response to SSRIs [73]. In this study, aspirin appeared to accelerate the response to antidepressants, as individuals presented a significant improvement of depressive symptoms in the first week of the trial [73]. One study did not report any additional clinical improvement with the combination of aspirin and fluoxetine compared to fluoxetine alone [74].

TNF- $\alpha$ antagonists have also been shown to exert positive effects on mood. In a large RCT involving individuals with psoriasis and without any diagnosed mental disorder, treatment with etanercept was associated with a significant reduction in depressive symptoms $[75,76]$. Infliximab, a monoclonal antibody directed at TNF- $\alpha$, was tested in a recent RCT for treatment-resistant MDD. Interestingly, infliximab was demonstrated to be more effective than placebo, but only in individuals with high baseline levels of a pro-inflammatory biomarker, the high-sensitivity CRP (defined as levels higher than $5 \mathrm{mg} / \mathrm{l}$ ) [77].

Other substances with known anti-inflammatory properties have also been explored in the treatment of depression. This group includes minocycline and antioxidants, such as curcumin, and $\mathrm{N}$-acetyl-cysteine (NAC) and zinc. Minocycline is an antibiotic with anti-inflammatory, antioxidant, antiglutamatergic and neuroprotec- 
tive effects [78]. Curcumin is a compound extracted from turmeric (Curcuma longa) and is commonly used as a culinary seasoning in different regions of Asia. Curcumin is believed to act in inflammatory, oxidative and apoptotic pathways [79]. To our knowledge, curcumin has not been used in clinical trials for depression so far. NAC is a glutathione precursor that has been shown to be involved in oxidative homeostasis, dopamine modulations and to interact with several inflammatory markers [80]. Preclinical studies with these agents have yielded promising results so far, with evidence supporting an antidepressantlike effect in animal studies [81-85].

Minocycline was tested in an open-label trial as an adjunctive therapy for patients with unipolar psychotic depression and demonstrated efficacy in both depressive and psychotic symptoms [86]. NAC use has been more extensively explored in bipolar depression. A 6-month doubleblind RCT of add-on NAC to standard treatment showed a significant positive effect for depressive symptoms and functional outcome $[87,88]$. However, a study using NAC for the maintenance of bipolar disorder observed no result in recurrence or symptomatic outcomes [89].

Reports that depression is associated with low blood zinc levels, which were increased by antidepressants, supports the idea that zinc homeostasis is involved in depression pathophysiology [90]. One placebo-controlled, double-blind pilot study of zinc supplementation to standard antidepressant therapy has been conducted [91]. In this study, patients who received zinc displayed a significant improvement after 6 and 12 weeks when compared to placebo controls [91].

\section{Exploration of Antidepressant Properties of}

Nonpharmacological Approaches That Modulate

\section{Inflammation}

Exercise is an efficacious treatment for MDD and has independently been shown to have anti-inflammatory effects in nondepressed subjects. In the Treatment with Exercise Augmentation for Depression (TREAD) study, participants who were partial responders to a selective serotonin reuptake inhibitor were randomized to receive one of two doses of exercise: 16 kilocalories per kilogram of body weight per week, KKW, or $4 \mathrm{KKW}$ for 12 weeks. Higher baseline levels of TNF- $\alpha$ were associated with a greater decrease in depressive symptoms over the 12 week exercise period. In addition, a significant positive correlation between change in IL-1 and reduction in depression symptom scores was observed [92].

Acupuncture is another alternative treatment that has shown some benefit in MDD. An RCT with individuals with mild-to-moderate depression demonstrated an improvement significantly higher than the placebo group [93], while a study using add-on acupuncture to paroxetine treatment obtained similar results [94]. Acupuncture has long been recognized to possess anti-inflammatory properties. Studies have shown that acupuncture can downregulate pro-inflammatory cytokines, including IL1, IL- 6 and TNF- $\alpha$, and pro-inflammatory neuropeptides [95]. This suggests that modulation of the inflammatory response can be one of the paths by which acupuncture ameliorates depressive symptomatology.

\section{Future Direction}

Overall, these results support the idea that targeting inflammatory pathways can be effective in the treatment of depression [95]. However, most clinical studies present important limitations in design, time or sample size. This fact hinders the drawing of definitive conclusions, as well as the translation to clinical practice. Nonetheless, what does the evidences gathered so far tell us about the future in this field of research? Firstly, the delimitation of subgroups can be a promising path. The clinical trial with infliximab obtained a positive result, but only for a 'highly inflamed' subgroup of patients [77]. The characterization of this group, using biomarkers (i.e. dosage of cytokines) and/or risk factor (i.e. childhood trauma) strategies, could lead to clinical trials with more refined designs. Secondly, the stage of illness should also be more carefully considered. Inflammation acts differently according to phase (acute vs. chronic) and duration (early vs. late stages) of the disease. Acute and severe states most likely represent the peak of pathological inflammatory activity and can indicate a moment when the introduction of anti-inflammatory agents would be more beneficial. The experience of NAC in bipolar disorder, which presented effective results in depressive episodes but not on maintenance [89], reinforces this concept. Moreover, many of the behavioral effects of inflammatory dysfunction, such as cognitive deficits, can be thought of as late consequences of it, which is probably the case in patients with longer-duration, multiepisodic illnesses [2]. As a consequence, they may not be as susceptible to interventions targeting inflammatory pathways. Therefore, these interventions may be better suited to individuals in the earliest stages of depression, before most of the damage has already been done. Finally, this last point can also be extrapolated for primary prevention strategies. Although this field of psychiatry is only in its infancy and its discussion is beyond the scope of this 
article, it is worth mentioning that anti-inflammatory interventions, especially the nonpharmacological ones, are ideal candidates for prevention studies. These interventions can have a disease-modifier effect, without the risk and side effects associated with psychotropic medications, and are therefore well-suited to use in groups with a high risk of developing depression, such as individuals with chronic diseases, history of childhood trauma or presence of subthreshold symptoms $[96,97]$.

\section{Conclusions}

There is ample evidence that MDD is accompanied by activation of inflammatory pathways, suggesting that these pathways are new drug targets in depression. Translation of these findings into new clinical trials with negative immunoregulatory or antioxidant drugs in MDD should be part of the scientific agenda for the coming years.

\section{References}

1 Maes M, Bosmans E, Suy E, Vandervorst C, De Jonckheere C, Raus J: Immune disturbances during major depression: upregulated expression of interleukin-2 receptors. Neuropsychobiology 1990;24:115-120.

-2 Leonard B, Maes M: Mechanistic explanations how cell-mediated immune activation, inflammation and oxidative and nitrosative stress pathways and their sequels and concomitants play a role in the pathophysiology of unipolar depression. Neurosci Biobehav Rev 2012;36:764-785.

3 Maes M: Evidence for an immune response in major depression: a review and hypothesis. Prog Neuropsychopharmacol Biol Psychiatry 1995;19:11-38.

4 Dean B, Tawadros N, Scarr E, Gibbons AS: Regionally-specific changes in levels of tumour necrosis factor in the dorsolateral prefrontal cortex obtained postmortem from subjects with major depressive disorder. J Affect Disord 2010;120:245-248.

5 Mesquita AR, Correia-Neves M, Roque S, Castro AG, Vieira P, Pedrosa J, Palha JA, Sousa N: IL-10 modulates depressive-like behavior. J Psychiatr Res 2008;43:89-97.

6 Song C, Wang H: Cytokines mediated inflammation and decreased neurogenesis in animal models of depression. Prog Neuropsychopharmacol Biol Psychiatry 2011;35:760-768.

7 Dowlati Y, Herrmann N, Swardfager W, Liu H, Sham L, Reim EK, Lanctot KL: A metaanalysis of cytokines in major depression. Biol Psychiatry 2010;67:446-457.

$\checkmark 8$ Maes M: Major depression and activation of the inflammatory response system. Adv Exp Med Biol 1999;461:25-46.

9 Licinio J, Wong ML: The role of inflammatory mediators in the biology of major depression: central nervous system cytokines modulate the biological substrate of depressive symptoms, regulate stress-responsive systems, and contribute to neurotoxicity and neuroprotection. Mol Psychiatry 1999;4:317327.
Zorrilla EP, Luborsky L, McKay JR, Rosenthal R, Houldin A, Tax A, McCorkle R, Seligman DA, Schmidt K: The relationship of depression and stressors to immunological assays: a meta-analytic review. Brain Behav Immun 2001;15:199-226.

11 Rief W, Pilger F, Ihle D, Bosmans E, Egyed B, Maes M: Immunological differences between patients with major depression and somatization syndrome. Psychiatry Res 2001;105:165174.

12 Liu Y, Ho RC, Mak A: Interleukin (IL)-6, tumour necrosis factor alpha (TNF- $\alpha$ ) and soluble interleukin-2 receptors (sIL-2R) are elevated in patients with major depressive disorder: a meta-analysis and meta-regression. J Affect Disord 2012;139:230-239.

13 Howren MB, Lamkin DM, Suls J: Associations of depression with C-reactive protein, IL-1, and IL-6: a meta-analysis. Psychosom Med 2009;71:171-186.

14 Shelton RC, Claiborne J, Sidoryk-Wegrzynowicz M, Reddy R, Aschner M, Lewis DA, Mirnics K: Altered expression of genes involved in inflammation and apoptosis in frontal cortex in major depression. Mol Psychiatry 2011; 16:751-762.

15 Maes M, Berk M, Goehler L, Song C, Anderson G, Galecki P, Leonard B: Depression and sickness behavior are Janus-faced responses to shared inflammatory pathways. BMC Med 2012;10:66.

16 Dantzer R: Cytokine-induced sickness behavior: mechanisms and implications. Ann NY Acad Sci 2001;933:222-234.

17 Dantzer R, O'Connor JC, Freund GG, Johnson RW, Kelley KW: From inflammation to sickness and depression: when the immune system subjugates the brain. Nat Rev Neurosci 2008;9:46-56.

18 Brietzke E, Kapczinski F: TNF- $\alpha$ as a molecular target in bipolar disorder. Prog Neuropsychopharmacol Biol Psychiatry 2008;32:13551361.

19 Sakic B, Gauldie J, Denburg JA, Szechtman H: Behavioral effects of infection with IL-6 adenovector. Brain Behav Immun 2001;15:25-42.
20 Kwant A, Sakic B: Behavioral effects of infection with interferon $-\gamma$ adenovector. Behav Brain Res 2004;151:73-82.

21 Kubera M, Obuchowicz E, Goehler L, Brzeszcz J, Maes M: In animal models, psychosocial stress-induced (neuro)inflammation, apoptosis and reduced neurogenesis are associated to the onset of depression. Prog Neuropsychopharmacol Biol Psychiatry 2011;35:744-759.

22 Maes M, Galecki P, Chang YS, Berk M: A review on the oxidative and nitrosative stress (O\&NS) pathways in major depression and their possible contribution to the (neuro)degenerative processes in that illness. Prog Neuropsychopharmacol Biol Psychiatry 2011;35: 676-692.

23 Lamers F, Vogelzangs N, Merikangas KR, de Jonge P, Beekman AT, Penninx BW: Evidence for a differential role of HPA-axis function, inflammation and metabolic syndrome in melancholic versus atypical depression. Mol Psychiatry 2013;18:692-699.

24 Hiles SA, Baker AL, de Malmanche T, Attia J: A meta-analysis of differences in IL- 6 and IL10 between people with and without depression: exploring the causes of heterogeneity. Brain Behav Immun 2012;26:1180-1188.

25 Thombs BD, Bass EB, Ford DE, Stewart KJ, Tsilidis KK, Patel U, Fauerbach JA, Bush DE, Ziegelstein RC: Prevalence of depression in survivors of acute myocardial infarction. J Gen Intern Med 2006;21:30-38.

26 Rugulies R: Depression as a predictor for coronary heart disease. a review and meta-analysis. Am J Prev Med 2002;23:51-61.

27 Liu H, Luiten PG, Eisel UL, Dejongste MJ, Schoemaker RG: Depression after myocardial infarction: TNF- $\alpha$-induced alterations of the blood-brain barrier and its putative therapeutic implications. Neurosci Biobehav Rev 2013; 37:561-572.

28 Brydon L, Edwards S, Jia H, Mohamed-Ali V, Zachary I, Martin JF, Steptoe A: Psychological stress activates interleukin- $1 \beta$ gene expression in human mononuclear cells. Brain Behav Immun 2005; 19:540-546. 
-29 Jaremka LM, Lindgren ME, Kiecolt-Glaser JK: Synergistic relationships among stress, depression, and troubled relationships: insights from psychoneuroimmunology. Depress Anxiety 2013;30:288-296.

-30 Kiecolt-Glaser JK, Gouin JP, Hantsoo L: Close relationships, inflammation, and health. Neurosci Biobehav Rev 2010;35:33-38.

-31 Brietzke E, Kauer Sant'anna M, Jackowski A, Grassi-Oliveira R, Bucker J, Zugman A, Mansur RB, Bressan RA: Impact of childhood stress on psychopathology. Rev Bras Psiquiatr 2012;34:480-488

- 32 Danese A, Moffitt TE, Pariante CM, Ambler A, Poulton R, Caspi A: Elevated inflammation levels in depressed adults with a history of childhood maltreatment. Arch Gen Psychiatry 2008;65:409-415.

- 33 Kubera M, Symbirtsev A, Basta-Kaim A, Borycz J, Roman A, Papp M, Claesson M: Effect of chronic treatment with imipramine on interleukin 1 and interleukin 2 production by splenocytes obtained from rats subjected to a chronic mild stress model of depression. Pol J Pharmacol 1996;48:503-506.

34 Maes M, Fisar Z, Medina M, Scapagnini G, Nowak G, Berk M: New drug targets in depression: inflammatory, cell-mediated immune, oxidative and nitrosative stress, mitochondrial, antioxidant and neuroprogressive pathways, and new drug candidates - Nrf2 activators and GSK-3 inhibitors. Inflammopharmacology 2012;20:127-150.

- 35 Berk M, Kapczinski F, Andreazza AC, Dean OM, Giorlando F, Maes M, Yucel M, Gama CS, Dodd S, Dean B, Magalhaes PV, Amminger P, McGorry P, Malhi GS: Pathways underlying neuroprogression in bipolar disorder: focus on inflammation, oxidative stress and neurotrophic factors. Neurosci Biobehav Rev 2011;35:804-817.

36 Moylan S, Maes M, Wray NR, Berk M: The neuroprogressive nature of major depressive disorder: pathways to disease evolution and resistance, and therapeutic implications. Mol Psychiatry 2013;18:595-606.

- 37 Grassi-Oliveira R, Bauer ME, Pezzi JC, Teixeira AL, Brietzke E: Interleukin-6 and verbal memory in recurrent major depressive disorder. Neuro Endocrinol Lett 2011;32:540-544.

- 38 Zou JY, Crews FT: TNFa potentiates glutamate neurotoxicity by inhibiting glutamate uptake in organotypic brain slice cultures: Neuroprotection by NFkB inhibition. Brain Res 2005;1034:11-24.

- 39 Hanisch UK, Neuhaus J, Rowe W, Van Rossum D, Moller T, Kettenmann H, Quirion R: Neurotoxic consequences of central longterm administration of interleukin-2 in rats. Neuroscience 1997;79:799-818.

-40 Liu D, Wang Z, Liu S, Wang F, Zhao S, Hao A: Anti-inflammatory effects of fluoxetine in lipopolysaccharide (LPS)-stimulated microglial cells. Neuropharmacology 2011;61:592599
41 Horikawa H, Kato TA, Mizoguchi Y, Monji A, Seki Y, Ohkuri T, Gotoh L, Yonaha M, Ueda T, Hashioka S, Kanba S: Inhibitory effects of SSRIs on IFN- $\gamma$ induced microglial activation through the regulation of intracellular calcium. Prog Neuropsychopharmacol Biol Psychiatry 2010;34:1306-1316.

42 Xia Z, DePierre JW, Nassberger L: Tricyclic antidepressants inhibit IL-6, IL- $1 \beta$ and TNF- $\alpha$ release in human blood monocytes and IL- 2 and interferon- $\gamma$ in T cells. Immunopharmacology 1996;34:27-37.

43 Ohgi Y, Futamura T, Kikuchi T, Hashimoto $\mathrm{K}$ : Effects of antidepressants on alternations in serum cytokines and depressive-like behavior in mice after lipopolysaccharide administration. Pharmacol Biochem Behav 2013;103:853-859.

44 Hannestad J, DellaGioia N, Bloch M: The effect of antidepressant medication treatment on serum levels of inflammatory cytokines: a meta-analysis. Neuropsychopharmacology 2011;36:2452-2459.

45 Ehrlich P: Das Sauerstoff-Bedürfniss des Organismus: Eine Farbenanalytische Studie. Berlin, Hirschwald, 1885.

46 Takeshita Y, Ransohoff RM: Inflammatory cell trafficking across the blood-brain barrier: chemokine regulation and in vitro models. Immunol Rev 2012;248:228-239.

47 Capuron L, Miller AH: Immune system to brain signaling: neuropsychopharmacological implications. Pharmacol Ther 2011;130: 226-238.

48 Plotkin SR, Banks WA, Kastin AJ: Comparison of saturable transport and extracellular pathways in the passage of interleukin-1a across the blood-brain barrier. J Neuroimmunol 1996;67:41-47.

49 Banks WA, Kastin AJ, Broadwell RD: Passage of cytokines across the blood-brain barrier. Neuroimmunomodulation 1995;2:241-248.

50 Watkins LR, Goehler LE, Relton JK, Tartaglia N, Silbert L, Martin D, Maier SF: Blockade of interleukin-1 induced hyperthermia by subdiaphragmatic vagotomy: evidence for vagal mediation of immune-brain communication. Neurosci Lett 1995;183:27-31.

51 Sallusto F, Impellizzieri D, Basso C, Laroni A, Uccelli A, Lanzavecchia A, Engelhardt B: Tcell trafficking in the central nervous system. Immunol Rev 2012;248:216-227.

52 Borkowska P, Kucia K, Rzezniczek S, PaulSamojedny M, Suchanek R, Owczarek A, Kowalczyk M, Fila-Danilow A, Kowalski J: Interleukin-1B promoter $(-31 \mathrm{~T} / \mathrm{C}$ and $-511 \mathrm{C} / \mathrm{T}$ ) polymorphisms in paranoid schizophrenia. Psychiatr Genet 2012;22:311.

-53 Bosker FJ, Hartman CA, Nolte IM, Prins BP, Terpstra P, Posthuma D, van Veen T, Willemsen G, DeRijk RH, de Geus EJ, Hoogendijk WJ, Sullivan PF, Penninx BW, Boomsma DI, Snieder H, Nolen WA: Poor replication of candidate genes for major depressive disorder using genome-wide association data. Mol Psychiatry 2011;16:516-532.
54 Uddin M, Koenen KC, Aiello AE, Wildman DE, de los Santos R, Galea S: Epigenetic and inflammatory marker profiles associated with depression in a community-based epidemiologic sample. Psychol Med 2011;41:997-1007.

55 Haastrup E, Bukh JD, Bock C, Vinberg M Thorner LW, Hansen T, Werge T, Kessing LV, Ullum H: Promoter variants in IL18 are associated with onset of depression in patients previously exposed to stressful-life events. J Affect Disord 2012;136:134-138.

56 Lanquillon S, Krieg JC, Bening-Abu-Shach U, Vedder $\mathrm{H}$ : Cytokine production and treatment response in major depressive disorder. Neuropsychopharmacology 2000;22:370-379.

57 Fornaro M, Rocchi G, Escelsior A, Contini P, Martino M: Might different cytokine trends in depressed patients receiving duloxetine indicate differential biological backgrounds. J Affect Disord 2013;145:300-307.

58 Maes M, Vandoolaeghe E, Neels H, Demedts P, Wauters A, Meltzer HY, Altamura C, Desnyder R: Lower serum zinc in major depression is a sensitive marker of treatment resistance and of the immune/inflammatory response in that illness. Biol Psychiatry 1997;42: 349-358.

59 Haroon E, Raison CL, Miller AH: Psychoneuroimmunology meets neuropsychopharmacology: translational implications of the impact of inflammation on behavior. Neuropsychopharmacology 2012;37:137-162.

60 Raison CL, Borisov AS, Broadwell SD, Capuron L, Woolwine BJ, Jacobson IM, Nemeroff $\mathrm{CB}$, Miller AH: Depression during pegylated interferon- $\alpha$ plus ribavirin therapy: prevalence and prediction. J Clin Psychiatry 2005; 66:41-48.

-61 Kendler KS, Karkowski LM, Prescott CA: Causal relationship between stressful life events and the onset of major depression. Am J Psychiatry 1999;156:837-841.

62 Raison CL, Miller AH: Is depression an inflammatory disorder? Curr Psychiatry Rep 2011;13:467-475.

63 Vogelzangs N, Kritchevsky SB, Beekman AT, Newman AB, Satterfield S, Simonsick EM, Yaffe K, Harris TB, Penninx BW: Depressive symptoms and change in abdominal obesity in older persons. Arch Gen Psychiatry 2008; 65:1386-1393.

64 Luppino FS, de Wit LM, Bouvy PF, Stijnen T, Cuijpers P, Penninx BW, Zitman FG: Overweight, obesity, and depression: a systematic review and meta-analysis of longitudinal studies. Arch Gen Psychiatry 2010;67:220229.

65 Nathan C: Epidemic inflammation: pondering obesity. Mol Med 2008;14:485-492.

66 Shelton RC, Miller AH: Eating ourselves to death (and despair): the contribution of adiposity and inflammation to depression. Prog Neurobiol 2010;91:275-299. 
67 Muller N, Schwarz MJ, Dehning S, Douhe A, Cerovecki A, Goldstein-Muller B, Spellmann I, Hetzel G, Maino K, Kleindienst N, Moller HJ, Arolt V, Riedel M: The cyclooxygenase-2 inhibitor celecoxib has therapeutic effects in major depression: results of a double-blind, randomized, placebo controlled, add-on pilot study to reboxetine. Mol Psychiatry 2006;11: 680-684.

68 Akhondzadeh S, Jafari S, Raisi F, Nasehi AA, Ghoreishi A, Salehi B, Mohebbi-Rasa S, Raznahan M, Kamalipour A: Clinical trial of adjunctive celecoxib treatment in patients with major depression: a double blind and placebo controlled trial. Depress Anxiety 2009;26:607-611.

-69 Akhondzadeh S, Tabatabaee M, Amini H, Ahmadi Abhari SA, Abbasi SH, Behnam B: Celecoxib as adjunctive therapy in schizophrenia: a double-blind, randomized and placebo-controlled trial. Schizophr Res 2007;90:179-185.

-70 Muller N, Krause D, Dehning S, Musil R, Schennach-Wolff R, Obermeier M, Moller HJ, Klauss V, Schwarz MJ, Riedel M: Celecoxib treatment in an early stage of schizophrenia: results of a randomized, double-blind, placebo-controlled trial of celecoxib augmentation of amisulpride treatment. Schizophr Res 2010;121:118-124.

-71 Muller N, Riedel M, Scheppach C, Brandstatter B, Sokullu S, Krampe K, Ulmschneider M, Engel RR, Moller HJ, Schwarz MJ: Beneficial antipsychotic effects of celecoxib add-on therapy compared to risperidone alone in schizophrenia. Am J Psychiatry 2002;159: 1029-1034.

-72 Fields C, Drye L, Vaidya V, Lyketsos C, ADAPT Research Group: Celecoxib or naproxen treatment does not benefit depressive symptoms in persons age 70 and older: findings from a randomized controlled trial. Am J Geriatr Psychiatry 2012;20:505-513.

-73 Mendlewicz J, Kriwin P, Oswald P, Souery D, Alboni S, Brunello N: Shortened onset of action of antidepressants in major depression using acetylsalicylic acid augmentation: a pilot open-label study. Int Clin Psychopharmacol 2006;21:227-231.

-74 Galecki P, Szemraj J, Bienkiewicz M, Zboralski K, Galecka E: Oxidative stress parameters after combined fluoxetine and acetylsalicylic acid therapy in depressive patients. Hum Psychopharmacol 2009;24:277-286.

-75 Krishnan R, Cella D, Leonardi C, Papp K, Gottlieb AB, Dunn M, Chiou CF, Patel V, Jahreis A: Effects of etanercept therapy on fatigue and symptoms of depression in subjects treated for moderate to severe plaque psoriasis for up to 96 weeks. Br J Dermatol 2007;157: 1275-1277.

76 Tyring S, Gottlieb A, Papp K, Gordon K, Leonardi C, Wang A, Lalla D, Woolley M, Jahreis A, Zitnik R, Cella D, Krishnan R: Etanercept and clinical outcomes, fatigue, and depression in psoriasis: double-blind placebocontrolled randomised phase III trial. Lancet 2006;367:29-35.
Raison CL, Rutherford RE, Woolwine BJ, Shuo C, Schettler P, Drake DF, Haroon E, Miller AH: A randomized controlled trial of the tumor necrosis factor antagonist infliximab for treatment-resistant depression: the role of baseline inflammatory biomarkers. JAMA Psychiatry 2013;70:31-41.

78 Soczynska JK, Mansur RB, Brietzke E, Swardfager W, Kennedy SH, Woldeyohannes HO, Powell AM, Manierka MS, McIntyre RS: Novel therapeutic targets in depression: minocycline as a candidate treatment. Behav Brain Res 2012;235:302-317.

79 Brietzke E, Mansur RB, Zugman A, Carvalho AF, Macedo DS, Cha DS, Abilio VC, McIntyre RS: Is there a role for curcumin in the treatment of bipolar disorder? Med Hypotheses 2013;80:606-612.

80 Asevedo E, Cunha GR, Zugman A, Mansur $\mathrm{RB}$, Brietzke E: N-acetylcysteine as a potentially useful medication to prevent conversion to schizophrenia in at-risk individuals. Rev Neurosci 2012;23:353-362.

81 Kulkarni S, Dhir A, Akula KK: Potentials of curcumin as an antidepressant. Sci World J 2009;9:1233-1241.

82 Molina-Hernandez M, Tellez-Alcantara NP, Perez-Garcia J, Olivera-Lopez JI, JaramilloJaimes MT: Desipramine or glutamate antagonists synergized the antidepressant-like actions of intra-nucleus accumbens infusions of minocycline in male Wistar rats. Prog Neuropsychopharmacol Biol Psychiatry 2008;32: 1660-1666.

-83 Molina-Hernandez M, Tellez-Alcantara NP, Perez-Garcia J, Olivera-Lopez JI, JaramilloJaimes MT: Antidepressant-like actions of minocycline combined with several glutamate antagonists. Prog Neuropsychopharmacol Biol Psychiatry 2008;32:380-386.

84 Xu Y, Ku BS, Yao HY, Lin YH, Ma X, Zhang YH, Li XJ: The effects of curcumin on depressive-like behaviors in mice. Eur J Pharmacol 2005;518:40-46.

85 Smaga I, Pomierny B, Krzyzanowska W, Pomierny-Chamiolo L, Miszkiel J, Niedzielska E, Ogorka A, Filip M: N-acetylcysteine possesses antidepressant-like activity through reduction of oxidative stress: behavioral and biochemical analyses in rats. Prog Neuropsychopharmacol Biol Psychiatry 2012;39:280287.

86 Miyaoka T, Wake R, Furuya M, Liaury K, Ieda M, Kawakami K, Tsuchie K, Taki M, Ishihara $\mathrm{K}$, Araki T, Horiguchi J: Minocycline as adjunctive therapy for patients with unipolar psychotic depression: an open-label study. Prog Neuropsychopharmacol Biol Psychiatry 2012;37:222-226.
7 Berk M, Copolov DL, Dean O, Lu K, Jeavons S, Schapkaitz I, Anderson-Hunt M, Bush AI: $\mathrm{N}$-acetyl cysteine for depressive symptoms in bipolar disorder - a double-blind randomized placebo-controlled trial. Biol Psychiatry 2008; 64:468-475.

88 Magalhaes PV, Dean OM, Bush AI, Copolov DL, Malhi GS, Kohlmann K, Jeavons S, Schapkaitz I, Anderson-Hunt M, Berk M: Nacetylcysteine for major depressive episodes in bipolar disorder. Rev Bras Psiquiatr 2011; 33:374-378.

89 Berk M, Dean OM, Cotton SM, Gama CS, Kapczinski F, Fernandes B, Kohlmann K, Jeavons S, Hewitt K, Moss K, Allwang C, Schapkaitz I, Cobb H, Bush AI, Dodd S, Malhi GS: Maintenance $\mathrm{N}$-acetyl cysteine treatment for bipolar disorder: a double-blind randomized placebo controlled trial. BMC Med 2012;10:91.

90 Swardfager W, Herrmann N, McIntyre RS, Mazereeuw G, Goldberger K, Cha DS, Schwartz Y, Lanctot KL: Potential roles of zinc in the pathophysiology and treatment of major depressive disorder. Neurosci Biobehav Rev 2013;37:911-929.

-91 Nowak G, Siwek M, Dudek D, Zieba A, Pilc A: Effect of zinc supplementation on antidepressant therapy in unipolar depression: a preliminary placebo-controlled study. Pol J Pharmacol 2003;55:1143-1147.

-92 Rethorst CD, Toups MS, Greer TL, Nakonezny PA, Carmody TJ, Grannemann BD, Huebinger RM, Barber RC, Trivedi MH: Pro-inflammatory cytokines as predictors of antidepressant effects of exercise in major depressive disorder. Mol Psychiatry 2013;18:1119-1124.

93 Andreescu C, Glick RM, Emeremni CA, Houck PR, Mulsant BH: Acupuncture for the treatment of major depressive disorder: a randomized controlled trial. J Clin Psychiatry 2011;72:1129-1135.

94 Qu SS, Huang Y, Zhang ZJ, Chen JQ, Lin RY, Wang CQ, Li GL, Wong HK, Zhao CH, Pan JY, Guo SC, Zhang YC: A 6-week randomized controlled trial with 4-week follow-up of acupuncture combined with paroxetine in patients with major depressive disorder. J Psychiatr Res 2013;47:726-732.

95 McDonald JL, Cripps AW, Smith PK, Smith CA, Xue CC, Golianu B: The anti-inflammatory effects of acupuncture and their relevance to allergic rhinitis: a narrative review and proposed model. Evid Based Complement Alternat Med 2013;2013:591796.

96 Garber J, Clarke GN, Weersing VR, Beardslee WR, Brent DA, Gladstone TR, DeBar LL, Lynch FL, D'Angelo E, Hollon SD, Shamseddeen W, Iyengar S: Prevention of depression in at-risk adolescents: a randomized controlled trial. JAMA 2009;301:2215-2224.

-97 Smit F, Ederveen A, Cuijpers P, Deeg D, Beekman A: Opportunities for cost-effective prevention of late-life depression: an epidemiological approach. Arch Gen Psychiatry 2006; 63:290-296.
Targeting the Inflammatory Pathway as a Therapeutic Tool for MDD
Neuroimmunomodulation 2014;21:131-139 DOI: $10.1159 / 000356549$ 